\title{
TEM Study of Nanoprecipitate Formation in Novel HSLA Steels
}

S. Deligiannis ${ }^{1}$, A. Alexandratou ${ }^{1}$, E. Flampouris ${ }^{1}$, P. Tsakiridis $^{1}$ and G. Fourlaris ${ }^{1}$

${ }^{1 .}$ Lab. of Physical Metallurgy, School of Mining and Metallurgical Engineering, National Technical University of Athens, Athens, Greece.

Over the last two decades, automotive and steel making producers have carried out research for developing novel high strength strip steels, focusing on enhanced, fuel efficient cars with reduced emissions, while preserving or even improving passenger safety and crash performance. High Strength Low Alloy (HSLA) strip steel products are of great importance to the automotive industry, since they are designed to provide an excellent combination of strength, formability and toughness [1].

Thermomechanical controlled processing (TMCP) of HSLA strip steels, suitably conditions the steel microstructure, resulting in a predominantly ferritic microstructure with formation of second phase nano-precipitates [2,3]. The influence of these fine precipitates on the overall mechanical properties of a steel grade, depends on the size, shape and their spatial distributions occurring when altering the TMCP parameters, such as the finishing temperature (FT), the coiling temperature (CT) or the cooling rates from FT to CT. Titanium, vanadium and niobium are the most significant micro-alloying elements acting as carbide and nitride formers, promoting grain refinement and dislocation mobility retardation [2]. The purpose of this study is to characterize and compare the microstructures of two novel experimental model HSLA grades, with controlled overall alloy compositions, based on titanium only and combined titanium-vanadium additions, assess the precipitation sequences via appropriate modification of FT and CT temperatures and correlate the observed precipitation sequences with attained mechanical properties.

The TMCP was carried out using a Gleeble 3500 thermomechanical simulation system. The thermomechanical treatment applied is depicted in fig.1. The coiling temperature (CT) was considered a variable for this study, in order to consider the effect on precipitation sequences of nitrides and carbides of titanium and vanadium within a ferritic matrix. For that reason, three coiling temperatures were employed: $750^{\circ} \mathrm{C}, 650^{\circ} \mathrm{C}$ and $550^{\circ} \mathrm{C}$. Cooling to room temperature was very slow, i.e. $1^{\circ} \mathrm{C} / \mathrm{s}$ (fig. 1 ).

The present study confirmed the role of CT on the strengthening of both steel grades following TMCP. Moreover, Vickers hardness evolution highlighted the significant strengthening observed on the Ti-V only samples coiled at $650^{\circ} \mathrm{C}$ in comparison to the Ti-only samples (fig. 2). The investigation of the microstructures confirmed the presence of fine precipitation of titanium carbonitrides in the $\mathrm{Ti}$ only grade (fig.3), while a second precipitation sequence of interphase vanadium carbides exists only for the Ti-V grade (fig.4). In addition, both grades exhibit grain boundary precipitation of coarse titanium nitrides which are responsible for the austenitic grain refinement during the finishing rolling passes [4].

\section{References:}

[1] Dae-Bum Park et al, Mater. Sci. Eng. A, 560 (2013), p. 528.

[2] I. Tamura et al, "Thermomechanical Processing of High-strength Low-alloy Steels", Butterworth \& Co. Ltd, 1988, p. 155.

[3] Y. Woo Kim et al, Mater. Sci. Eng. A, 615 (2014), p. 255. 
[4] S. Deligiannis is grateful for financial support, kindly provided by the Eugenides Foundation (Athens, GR).
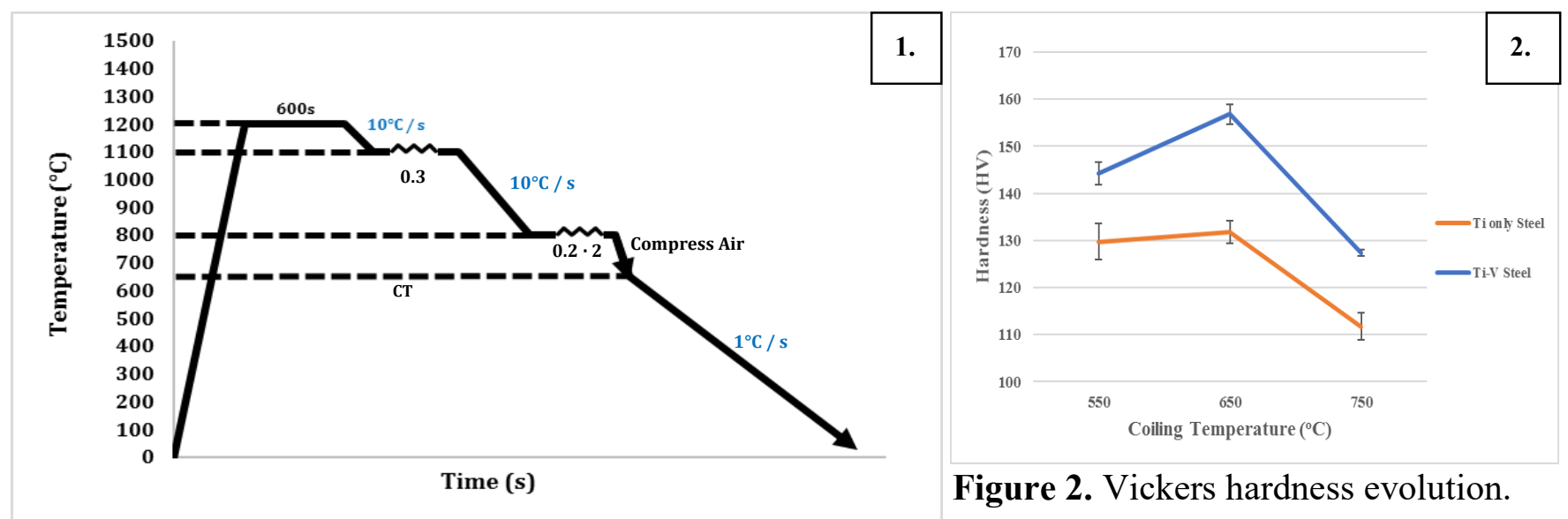

Figure 2. Vickers hardness evolution.

Figure 1. TCMP sequences applied.
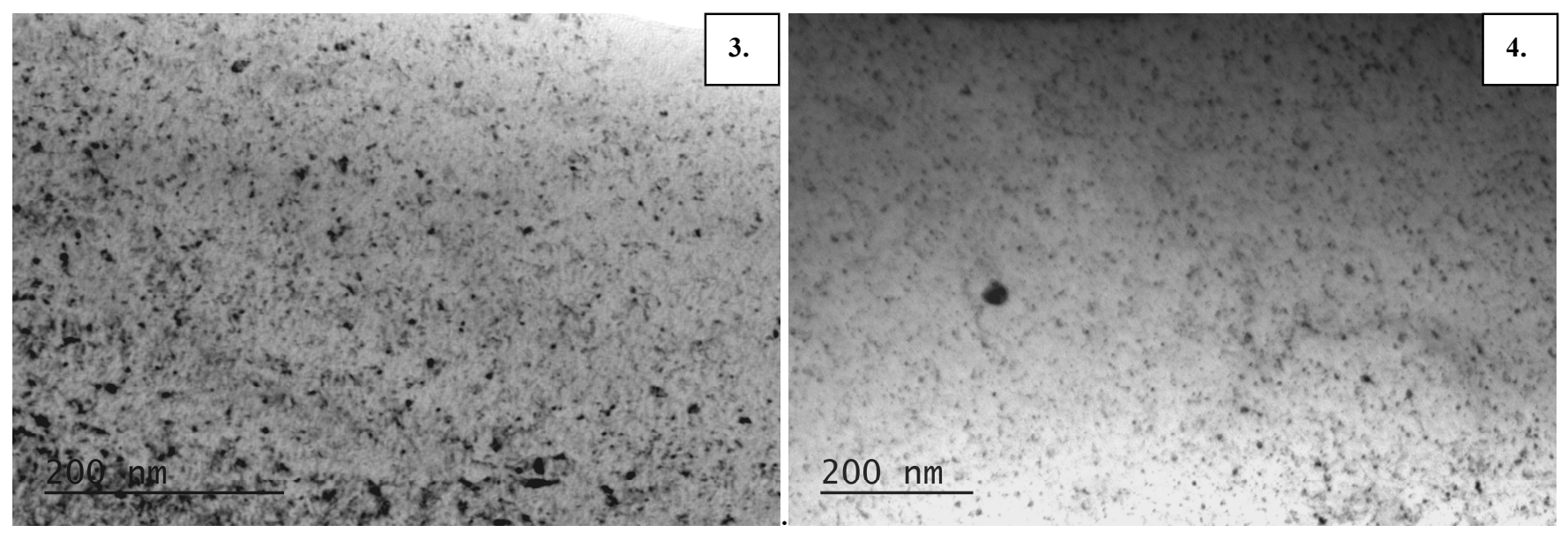

Figure 3. BF TEM micrograph of Ti-only sample Figure 4. BF TEM micrograph of the Ti-V sample $\left(\mathrm{CT}=650^{\circ} \mathrm{C}\right)$, showing the distribution of $\mathrm{TiC}\left(\mathrm{CT}=650^{\circ} \mathrm{C}\right)$, showing the distribution of $\mathrm{VC}$ precipitates $(\approx 10 \mathrm{~nm})$ within the ferrite. precipitates $(\approx 10 \mathrm{~nm})$ within the ferrite. 